\title{
ARID2 Chromatin Remodeler in Hepatocellular Carcinoma
}

\author{
Robin Loesch ${ }^{1,2}$, Linda Chenane ${ }^{1,2}$ and Sabine Colnot ${ }^{1,2, *(1)}$ \\ 1 INSERM, Centre de Recherche des Cordeliers (CRC), Sorbonne Université, Université de Paris, F-75006 Paris, \\ France; robin.loesch@inserm.fr (R.L.); chenane.linda.19@gmail.com (L.C.) \\ 2 Equipe labellisée "Ligue Nationale Contre le Cancer", F-75013 Paris, France \\ * Correspondence: sabine.colnot@inserm.fr
}

Received: 30 July 2020; Accepted: 16 September 2020; Published: 23 September 2020

check for updates

\begin{abstract}
Chromatin remodelers are found highly mutated in cancer including hepatocellular carcinoma. These mutations frequently occur in ARID (AT-rich Interactive Domain) genes, encoding subunits of the ATP-dependent SWI/SNF remodelers. The increasingly prevalent complexity that surrounds the functions and specificities of the highly modular BAF (BG1/BRM-associated factors) and PBAF (polybromo-associated BAF) complexes, including ARID1A/B or ARID2, is baffling. The involvement of the SWI/SNF complexes in diverse tissues and processes, and especially in the regulation of gene expression, multiplies the specific outcomes of specific gene alterations. A better understanding of the molecular consequences of specific mutations impairing chromatin remodelers is needed. In this review, we summarize what we know about the tumor-modulating properties of ARID2 in hepatocellular carcinoma.
\end{abstract}

Keywords: ARID2; hepatocellular carcinoma; cancer; chromatin; SWI/SNF

\section{Introduction to the SWI/SNF Chromatin Remodeling Complexes}

Gene expression regulation is far from being a random phenomenon. It requires covalent modifications targeting both DNA via methylation, and histones via post-translational modifications (PTM), which shape the nucleosomes and control the DNA compaction into chromatin and the recruitment of specific transcription factors. The level of DNA compaction is highly dynamic and dictated by multiple and diverse histone PTM [1] and/or by the extent of nucleosome occupancy, which is modulated via a mechanism called nucleosome remodeling. ATP-dependent chromatin remodelers form large complexes are capable of physically remodeling the landscape of histones and factors on the DNA. Such complexes, like the BRG1/BRM-associated factors (BAF) and polybromo-associated BAF (PBAF) complexes (frequently referred to as the mammalian SWI/SNF complexes), have been widely implicated in transcriptional regulation and biological processes including development, differentiation, and cancer $[2,3]$.

The identification of SWI/SNF subunits was a case of ultimate serendipity. Subunits were identified in two independent genetic screens in Saccharomyces cerevisiae. The first aimed to identify signal transduction molecules needed for the response to mating factors that lead to mating-type switching (SWI). The other screen was designed to identify signaling molecules leading to sucrose fermentation in response to nutrient switching in yeast (SNF; sucrose nonfermenting) [4,5]. The SWI/SNF components are related to the Trithorax family (TrxG), found in flies, to antagonize the polycomb group (PcG) proteins, in order to regulate Hox genes precisely [6]. The coevolution of the PcG and TrxG was accompanied by an increase in complexity. Mammalian PcG complex components are now separated into 3 complexes: the polycomb repressive complex 1 and 2 (PRC1/2) and the polycomb repressive deubiquitinase complex (PR-DUB). As for mammalian TrxG complex components, they are separated 
into the SWI/SNF and the COMPASS family. Mammalian SWI/SNF multiprotein complexes (Figure 1A) are now well described and appear, like PcG complexes, highly modular. BAF and PBAF SWI/SNF complexes are composed of 10 to 15 subunits, some of which are specific to the BAF (ARID1A/B; SS18/L1; DPF 1/2/3) or the PBAF (ARID2; BRD7; PBRM1; PHF10) complex. Shared subunits constitute the BAF core, composed of the SMARC subfamily members, and an ATPase module, containing the ATPase subunit BRM or BRG1 (SMARCA2 and SMARCA4 respectively). The precise mechanisms by which SWI/SNF complexes regulate gene expression are various and poorly understood. Early observations indicated that SWI/SNF complexes are capable of ATP-dependent nucleosome displacement and ejection which can be inhibited by histone mutants (Figure 1B) [7,8]. A recent study suggests different models by which the BAF complex can induce nucleosome ejection by itself and/or as a result of topological constraints [9]. Independently of nucleosome remodeling properties, SWI/SNF complexes could act as docking/recruitment platforms for epigenetic regulators as they have been shown to work alongside histone acetyltransferases (HATs) [10,11]. SWI/SNF complexes also notably appear to either antagonize polycomb-mediated repression or promote repression by polycomb in stem cells and cancer cells $[3,12,13]$. A study describing the role of the ATPase subunit in the composition and function of BAF and PBAF recently shed light on the regulation of those complexes. Pan et al. found that a residual BAF and PBAF complex can bind chromatin at overlapping sites in the absence of the ATPase subunit [14]. In this case, BAF and PBAF divergent localization on DNA was restored upon rescue of the ATPase subunit. Furthermore, a subset of binding sites are independent of the ATPase activity, supporting the idea that SWI/SNF functions are not necessarily linked to nucleosome remodeling. Moreover, this study supports the fact that the incorporation of specific subunits is potentially responsible for the SWI/SNF targeting.

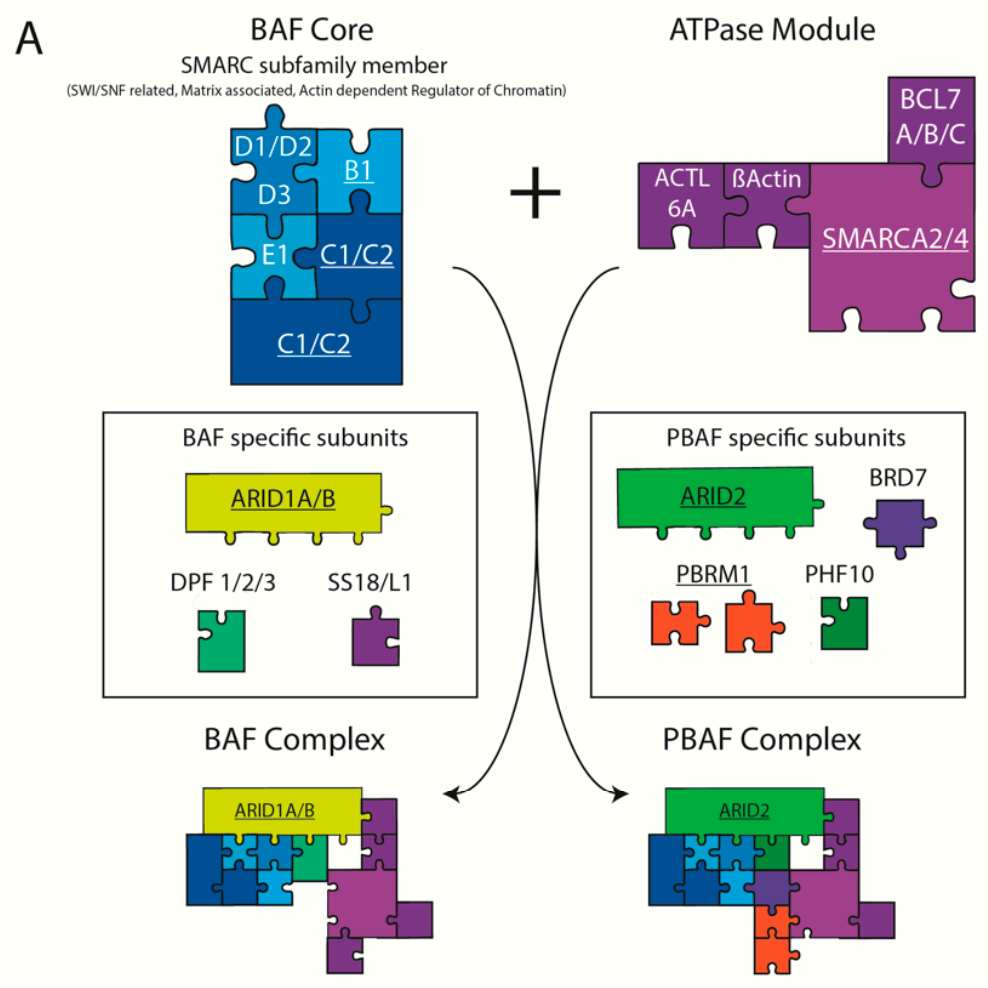

Figure 1. Cont. 
B

1.

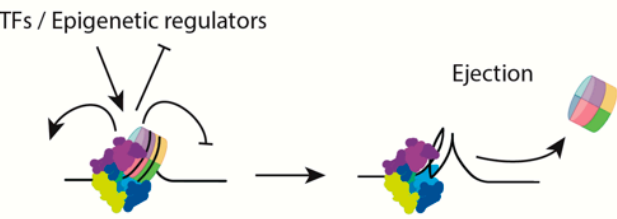

2.

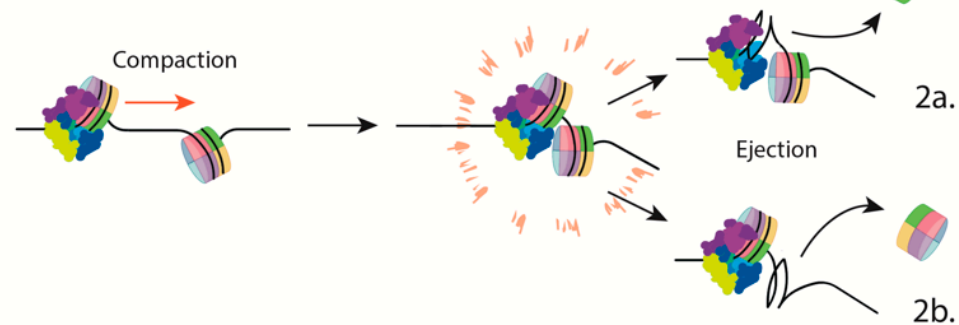

Figure 1. Structure and function of BAF/PBAF complexes. (A) Composition of the combinatory BAF and PBAF complexes. Multiple variant of the SMARC family members can be incorporated in the BAF core or the ATPase module. Addition of BAF and PBAF-specific subunits increases the combinatory potential of SWI/SNF complexes. Underlined subunits are found mutated in cancers. (B) Models of ATP-dependent SWI/SNF-mediated nucleosome remodeling. In the first model, SWI/SNF complex can eject nucleosome (1) while in the second one, DNA tension created by nucleosome sliding induces ejection of the adjacent $(\mathbf{2} \mathbf{b})$ or complex-bound (2a) nucleosome.

Back in the late 1990s, the bi-allelic alteration of the SWI/SNF subunit SMARCB1 was first thought to contribute to oncogenesis in highly malignant childhood neoplasms [15]. The development of high-throughput sequencing technologies these last two decades has revealed more and more somatic mutations damaging SWI/SNF subunits in malignancies. Indeed, nearly fifty sequencing studies have revealed that several subunits of mammalian SWI/SNF are mutated in $\sim 20 \%$ of the analyzed cancer types $[2,16]$. ARID2 mutations were first identified in hepatocellular carcinoma (HCC) which suggested a tumor suppressive activity $[17,18]$. Here we review the current knowledge about the involvement of ARID2 in cancer in general and in HCC more specifically.

\section{ARID2, Structure and Regulation}

ARID2, for AT-rich interactive domain 2, is a 1835 amino acid long protein encoded by ARID2 gene on chromosome 12q (Figure 2B). ARID2 was first identified in a yeast two-hybrid screen as the Zipzap/p200 protein interacting with SRF (Serum Response Factor) [19]. In showing the activation potential of Zipzap/p200 on cardiac genes during development, a role for ARID2 as a transcriptional co-activator was proposed. Its name comes from the AT-rich DNA interaction domain (ARID) found in N-terminal which is common to the ARID protein family [20]. Like the other ARID members of the SWI/SNF complexes, ARID2 binds DNA without sequence specificity [21], but it is still unclear to what extent the ARID domain is important to the PBAF complex. Overall, the functionality of each ARID2 protein domain is still poorly known.

ARID2 contains two additional DNA-binding domains: an evolutionary conserved RFX domain [22] and a tandem $\mathrm{C} 2 \mathrm{H} 2$ zinc finger domain, and one protein-protein interaction domain LXXLL. A recent study from Kadoch laboratory suggests that the core binding domain involved in the docking of ARID2 to the BAF core module extends from the ARID domain to the RFX domain [23]. A large proline and glutamine-rich domain is found in the middle of ARID2, but its function is still unknown. Such a domain is found in many transcription factors and might be important for protein-protein interaction. The conservation among mammals of the three DNA binding domains in ARID2 protein suggests a role in the binding of PBAF complex to the nucleosome-associated DNA. ARID2 was first shown to be the only subunit with a short half-life. ARID2 decreased expression, either by depletion using small interfering RNA [24] or CRISPR [25], leads to a diminution of other PBAF-specific subunits. 
It is in keeping with the recent description of the SWI/SNF complex assembly [23] that shows that ARID2 initiates PBAF assembly and is important for the recruitment and stability of PBAF-specific subunits.

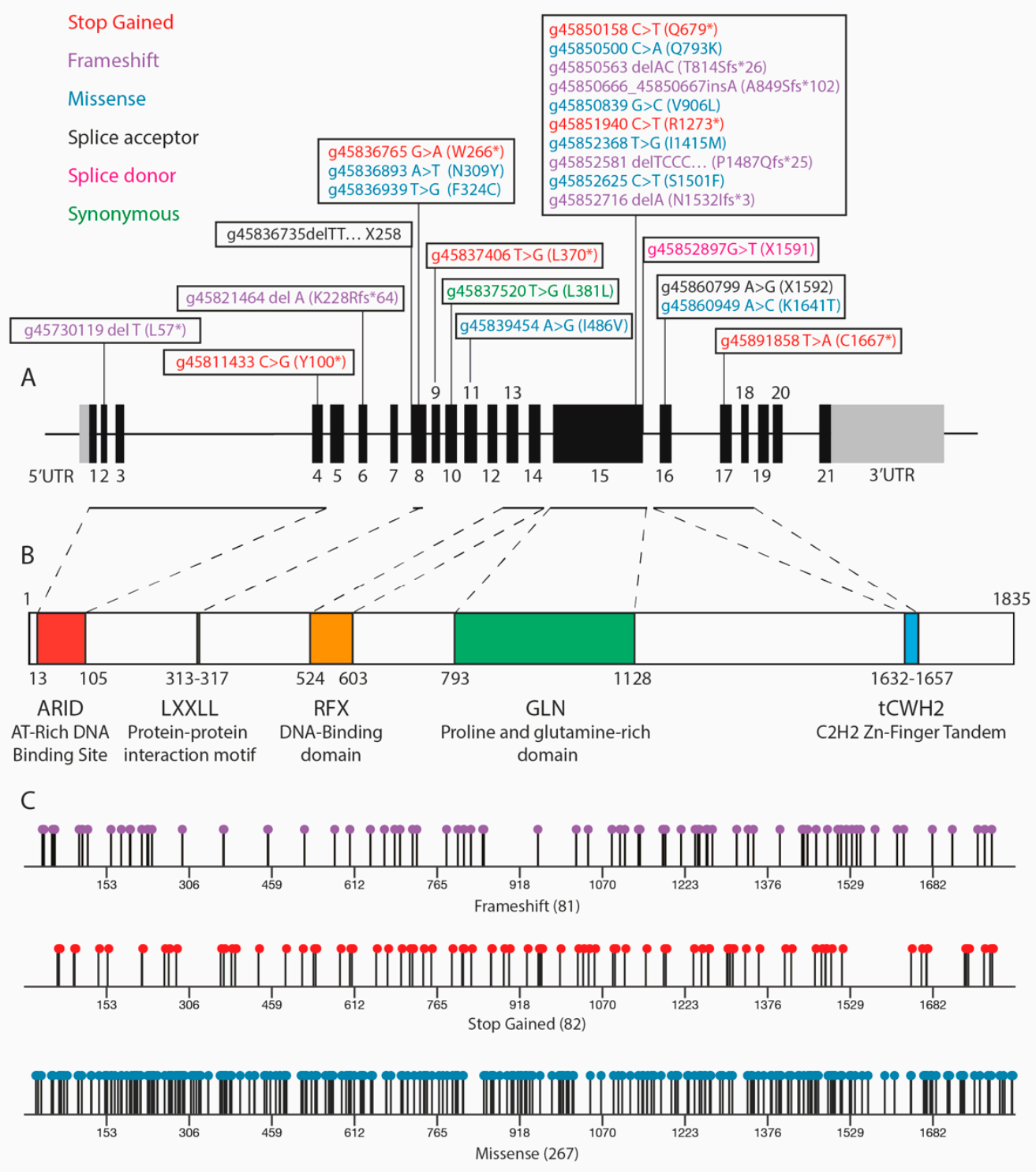

Figure 2. ARID2 gene and protein, with gene mutations found in cancer. (A) ARID2 gene structure along with mutations found in human hepatocellular carcinoma (HCC). (B) ARID2 protein structure with known domains. (C) Positions and nature of ARID2 mutations found in cancer (pan-cancer, The Cancer Genome Atlas (TCGA) data).

\section{ARID2 in Development and Pathophysiology}

Related to its involvement in PBAF complex, ARID2 has been rapidly involved in the regulation of tissue-specific gene expression [26]. ARID2 is expressed in the majority of murine tissues, starting from embryonic stage E8, and is vital for normal embryonic development [27]. In vivo insertion of LacZ cDNA into Arid 2 murine locus, resulting in a hypomorphic Arid 2 mutant allele, reveals many heart impairments underlying the essential role of Arid2 in the proliferation of embryonic cardiomyocytes and their developmental fate. The conditional deletion of ARID2 in endothelial cells and hematopoietic lineages using a Cre-lox approach in mice led to the reduction of the absolute cell number in fetal liver at mid-gestation (E13.5), severe anemia, growth delay starting from early E15.5, and embryonic death by E18.5 [28]. Moreover, Fuhua et al. used a shRNA approach to deplete ARID2 expression 
in undifferentiated MC3T3-E1 pre-osteoblasts (committed to the osteoblast lineage) and found that ARID2 is required for osteogenic differentiation [26].

Consistent with early studies linking the SWI/SNF complexes to the expression of interferon responsive genes [29-33], Yan et al. [24] showed that knockdown of ARID2 in Hela and HCC1143 cells specifically inhibits the induction of a subset of interferon-induced genes such as Ifitm1 (Interferon-Induced Transmembrane Protein 1).

PBAF complex and especially ARID2 were additionally reported to be involved in DNA damage response (DDR). In their study, Kakarougkas et al. [34] not only described the need for PBAF complex to silence transcription flanking DNA breaks, but also showed that PBAF acts jointly with PcG proteins to ensure efficient repair. Furthermore, they showed that PBRM1 phosphorylation by the serine/threonine kinase ATM is required for both repair and transcriptional silencing and cannot be rescued by a cancer-associated PBRM1 mutant. In another recent study showing the implication of ARID2 in DDR, de Castro et al. [35] showed that ARID2 interacts with RAD51, a protein involved in DNA repair of double strand breaks (DSB), and makes its recruitment easier into DSB sites upon repair via homologous recombination. Additionally, they showed that ARID2 and RAD51 interact via their C-terminal domain.

Lastly, in addition to cancers, some neurodevelopmental disorders have been linked to mutations in SWI/SNF complexes (BAFopathies) [36]. This is the case for de novo heterozygous ARID2 mutations, which have been linked to the Coffin-Siris syndrome 6 (CSS6), a rare genetic intellectual disorder characterized by a mild to severe developmental or cognitive delay [37,38]. In CSS6, unique variants were found across the ARID2 gene and predicted to disrupt ARID2 functions via frameshift or substitution. Four independent patients harboring either an ARID2 mutation at the beginning of the protein ( 2 of them) or next to the zinc finger motif, were found to have very similar CSS-like phenotypes which suggests that global heterozygous ARID2 loss-of-function (LoF) can cause CSS syndrome due to haploinsufficiency. However, as of now, no malignancies have yet been reported in CSS6 patients. This might be because a full loss of ARID2 is required for a tumorigenic effect or because ARID2 loss alone is not sufficient to promote oncogenesis.

\section{ARID2 in Cancer}

ARID2 mutations have been reported in many human cancers including melanoma, urothelial cancer, gastric adenocarcinoma, non-small cell lung cancer, HCC, and more [16]. Sequencing data from The Cancer Genome Atlas (TCGA) do not reveal major mutation hotspots in ARID2 and alterations are spread all along the gene in all cancers, including HCC (Figure 2A,C). Therefore, it is possible that the oncogenic features of mutated ARID2 are not mediated by the loss of a specific domain but rather by the global loss-of-function (LoF) of ARID2, most probably impacting PBAF functions. Several studies suggested or reported ARID2 tumor suppressor properties [18,39,40]. Exome data in melanoma showed a higher LoF mutation burden in ARID2 than expected by chance [41] and nonsense mutations were predicted to lead to truncated proteins lacking the $\mathrm{C} 2 \mathrm{H} 2$ zinc finger domain. ARID2 was also found mutated in 5\% of non-small cell lung carcinoma and, as for HCC, in a TP53 non-mutated background [40].

While SWI/SNF complexes and ARID2 have been involved in both DDR and gene regulation, it is still not clear to what extent their tumor suppressive effect is due to impaired DDR or aberrant transcriptional regulation. However, there are some clues as to what might be happening. The recent description of PBAF complex assembly suggests that ARID2 or PBRM1 loss could lead to similar consequences. PBRM1 germline mutations in clear cell renal cell carcinoma are not associated with increased chromosomal abnormalities or an increased mutational burden, nor are germline SMARCB1 mutations in rhabdoid tumors, suggesting that SWI/SNF-mediated DDR is poorly or not involved in chromosomal stability in these cases. Another piece of information is that in vitro rescue of a functional SWI/SNF complex is frequently associated with a decrease in cellular proliferation and death [42,43]. 
If the loss of ARID2 or PBAF complex can impair DDR, an aberrant transcriptional regulation is more likely to be responsible for the tumor suppressive properties.

Finally, Arid2, together with Pbrm1 [44], is linked to cancer cell immunotherapy resistance [25]. Its expression inversely correlates with the expression of genes related to $\mathrm{T}$ cell cytotoxicity in several human cancers. Inactivation of Arid2 in B16-F10 melanoma cells makes them sensitive to $\mathrm{T}$ cell-mediated killing and enhances IFN $\gamma$ response. ARID2-mutated cancers are therefore expected to offer a greater tumor susceptibility to immunotherapies.

\section{ARID2 in Hepatocellular Carcinoma (HCC)}

HCC is an example of cancer that frequently harbors ARID2 mutations. HCC is the most frequent primary liver cancer for which patients are often diagnosed at advanced stages and only unsatisfactory treatment options are available. Although early-stage tumors can be cured using surgical approaches, less than $30-40 \%$ of HCC patients are eligible for such curative therapeutic options. For patients with unresectable HCC, multikinase inhibitors (TKI) such as sorafenib and lenvatinib are used to limit disease progression. A protocol has recently emerged combining TKI treatments with immunotherapies to better improve patient survival, giving hope to patients [45]. HCC is a highly heterogeneous cancer, frequently occurring in a context of cirrhosis, and related to etiologies including viral hepatitis $\mathrm{C}$ and $\mathrm{B}(\mathrm{HCV}$ and $\mathrm{HBV})$, alcohol intake, and non-alcoholic steatohepatitis [46]. Moreover, HCC development relies on a complex multistep process involving different genetic alterations and deregulated signaling pathways [46]. Recent high-throughput genomic analyses have converged on mutational hotspots in human HCC confirming telomerase expression, $\beta$-catenin signaling, TP53 related signaling, and chromatin modifications among the core deregulated pathways in HCC initiation and/or progression [47-50] (Figure 3).
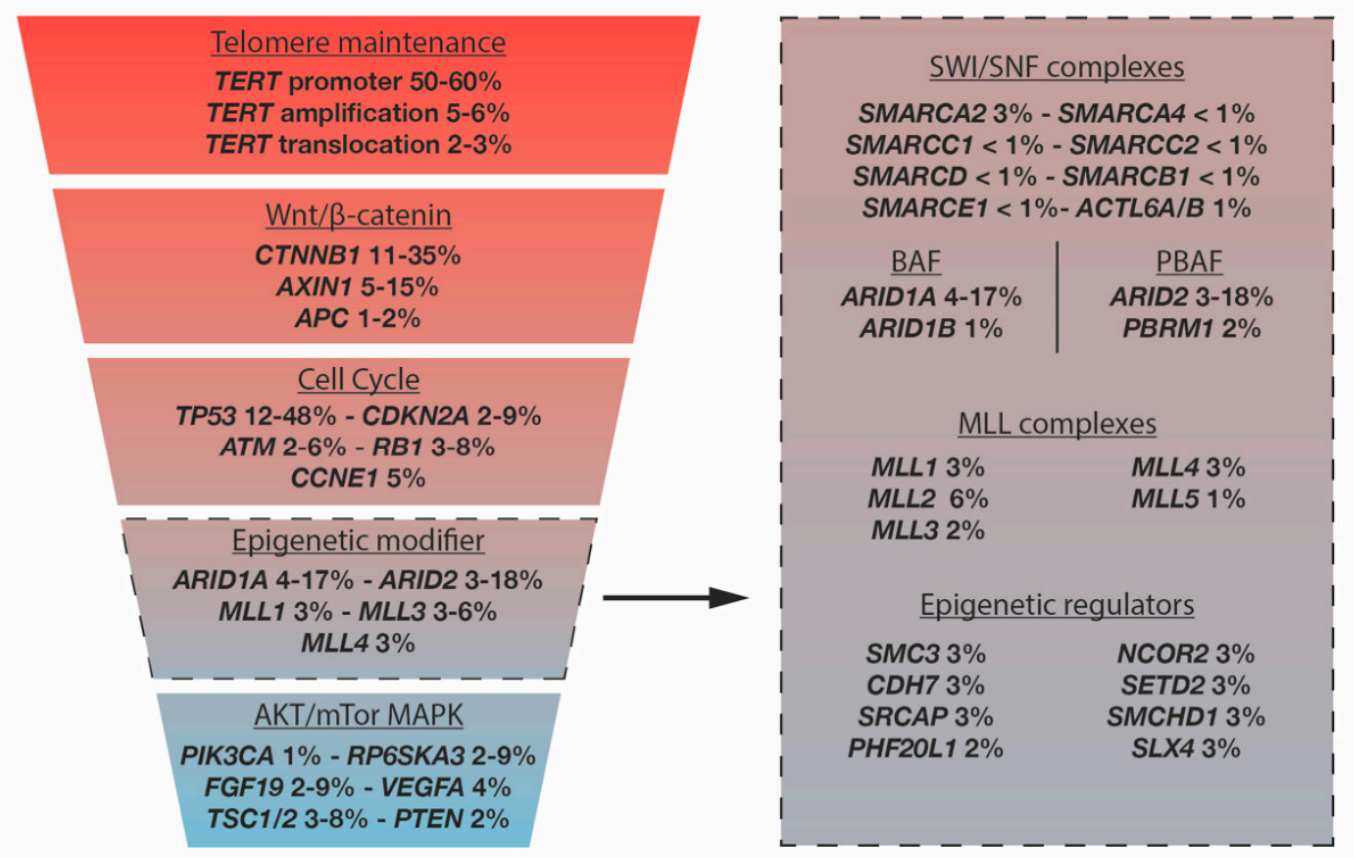

Figure 3. Hepatocellular carcinoma mutational landscape. The left part of the figure shows the different pathways affected by gene alterations in HCC, with the percentage of mutations; the right part shows mutations in epigenetic modifiers, the most frequently mutated being ARID1A and ARID2 (Adapted from Nault, J Hepatol 2014 [51]). 


\subsection{Arid2 Suppressing Function in HCC}

\subsubsection{Mutational Inactivation}

Early exome sequencing studies investigated the mutational landscape in HCC, and ARID2 inactivating mutations were the first to be identified among the SWI/SNF chromatin remodeler family in 2011 by Li and Zhao and colleagues [17,18]. Exon sequencing of 139 HCC found expected mutations in previously described genes like CTNNB1 or TP53 and unexpectedly LoF mutations in ARID2. ARID2 alterations consist in frameshift-inducing insertion or deletion (indels), nonsense mutations, and splice-site mutations with no major hotspot of mutations (Figure 2A). In agreement with a more recent study [52], ARID2 mutations were found correlated with CTNNB1 mutations (in 6 out of 9 HCC) and mutually exclusive with TP53 mutations. ARID2 mutations were also found to occur more often in HCV-related HCCs (6/43) than in HBV (1/50) or non-viral (2/44) related HCC.

\subsubsection{MiRNA-Mediated Down-Regulation}

MicroRNAs (miRNAs) are small noncoding RNAs which post-transcriptionally repress gene expression. Their widespread role in processes driving tumor initiation and progression is recognized [53]. Interestingly, multiple miRNAs (miR) were found to decrease ARID2 levels in $\mathrm{HCC}$, thereby promoting tumor growth and invasion $[54,55]$.

- MiR-208 was described to promote cell proliferation in human esophageal squamous cell carcinoma [56], promote EMT in pancreatic cancer cells [57], stimulate tumorigenesis in colorectal cancer [58], suppress cell apoptosis in gastric cancer [59], or to facilitate cell proliferation and invasion in non-small cell lung cancer and in hepatocellular carcinoma [54,60]. In 2015, miR-208-3p was found to be transcriptionally regulated by TGFß1 and to directly target ARID2 [54]. ARID2 downregulation, mediated by miR-208-3p, decreased proliferation and invasion in HepG2 and Hep3B hepatoma cell lines. Tumor growth was impaired after subcutaneous injection of Hep3B cells transfected with a miR-208-p3 inhibitor. In vitro, ARID2 restoration partially reversed the effect of miR-208-p3 inhibitor on proliferation and invasion. Altogether experimental data link TBFß signaling to ARID2 downregulation through miR-208-3p, leading to HCC cell proliferation and invasion.

- $\quad$ Mir-376c was described to be abnormally expressed, acting either as an oncomiR in ovarian cancer [61] and colorectal cancer [62] or as a tumor suppressor in melanoma [63]. Mir-376c was found to be upregulated in a screen for dysregulated miRNA in chronic HBV-associated HCC [64]. Further analysis found that miR-376c-3p expression promotes proliferation, migration, and invasion in Hep3B and SMMC-7721 cell lines through direct targeting of ARID2 via its 3'-UTR. As for miR-208, miR-376c-3p knockdown using an inhibitor restrained tumor growth in a xenograft mice model using Hep3B cells. In addition, miR-376c-3p expression was found to be significantly higher in HCC samples compared to non-tumor-adjacent tissues while ARID2 was inversely downregulated in HCC samples.

- Mir-155 is one of the most studied oncomiR that has an extensive role in malignant and non-malignant diseases [65]. Mir-155 appears to play multiple roles in HCC. Some evidence link miR-155 to (1) HCC cell proliferation via downregulation of PTEN [66,67]; (2) TGFß mediated epithelial-mesenchymal transition (EMT) [68]; (3) Wnt/ß-catenin signaling activation via downregulation of $A p c$ during HCV infection [69]; (4) suppression of the tumor suppressor gene FBXW7 [70]. Furthermore, two studies describe ARID2 as a direct target of miR-155 [71,72].

\subsection{ARID2 is a Tumor-or Metastasis-Suppressor in HCC}

In 2016, a lower expression of ARID2 was globally found in tumoral tissue versus non-tumoraladjacent tissue in $40 \mathrm{HCC}$ samples, both at the mRNA and protein levels [73]. By overexpressing ARID2 in HCC cell lines (ARID2-Up), Duan et al. were able to suppress cell proliferation and migration in 
HCC cell lines, while downregulation of ARID2 by siRNA-mediated knockdown (ARID2-Kd) increased cell proliferation and migration capacities. ARID2-dependent proliferation was further confirmed in an orthotopic xenograft model using Arid2-Up or Arid2-Kd HCC cell lines. Using HCC cell lines with ectopic expression of E2F1, ARID2 downregulation was linked to Rb-E2F signaling and associated with transcriptional upregulation of E2F1, cyclins D1 and E1, CDK4, as well as Rb phosphorylation. ARID2 interacted with E2F1 and this was associated to cyclin D1/E1 repression via dissociation of E2F1 and RNA pol II from CCND1 and CCNE1 promoters. Duan et al. suggested a mechanism through which ARID2 controls cell proliferation by regulating the expression of cell cycle components. More recently, Jiang et al. described ARID2 downregulation in metastatic HCC, in association with poor prognoses [74]. ARID2-Kd was associated with increased migration and invasion in HCC cell lines whereas ARID2 over-expression in HCC cell lines and their related metastatic derivative inhibited invasion and migration. The suppressive effect of ARID2 on metastasis was further studied in vivo. When injected in mouse livers, the metastatic potential of HCC cell lines was reduced when ARID2 was overexpressed, while in contrast, this metastatic potential increased after ARID2 knockdown. Using a Cre-loxP mouse model of hepatic specific Arid 2 deletion (Arid $2^{\mathrm{ko}}$ ), in a context of chemically (DEN) or genetically (via TP53 deletion and Ras ${ }^{\mathrm{G} 12 \mathrm{D}}$ oncogene expression) induced carcinogenesis, the authors additionally demonstrated that ARID2 acts as a metastasis suppressor in HCC. ARID2 was found in HCC cell lines to downregulate mesenchymal markers such as Snail and upregulate epithelial markers such as E-cadherin. This suggested a suppressing effect of Arid2 on EMT which was supported by the induction of an EMT signature found in the transcriptome of primary Arid ${ }^{\mathrm{ko}}$ mouse hepatocytes. Focusing on Snail transcriptional factor, the authors described the binding of Arid2 on Snail promoter via interaction of $\mathrm{C} 2 \mathrm{H} 2$ domain of Arid2 with Dnmt1. Further in vitro experiments supported a model in which Arid2 promotes Dnmt1 recruitment to Snail promoter, inducing promoter methylation and subsequent downregulation of Snail expression. Finally, the authors provided evidence that mutation of Arid2 $\mathrm{C} 2 \mathrm{H} 2$ domain abolishes its metastasis suppressor function by losing its ability to recruit Dnmt1 to Snail promoter.

The loss of function of ARID2 was also shown to affect DNA repair in HCC. Regarding tumor initiation, one in vitro study [75] describes a role for ARID2 in recruiting XPG (xeroderma pigmentosum complementation group G), a component of the nucleotide excision repair (NER), upon UV irradiation or exposure to carcinogenic chemical compounds like benzo\{a\}pyrene and $\mathrm{FeCl} 3$. Such a defect in NER mechanism could induce an accumulation of somatic mutations leading to tumorigenesis in the liver, but it still needs further demonstration.

\section{Towards Therapies against HCC by Targeting ARID2}

ARID2 is emerging as a tumor metastasis suppressor gene in HCC and cancer in general (Figure 4). For now, some underlying mechanisms have been described in liver cancer cells, such as ARID2 interaction with E2F1 to control the cell cycle or its interaction with Dnmt1 to control EMT and invasive/metastatic processes. SWI/SNF functions have already been found highly dependent on the tissue context. In this matter, it appears that mutations of SWI/SNF components can, most likely, induce very cancer-specific features. It also implies that appropriate in vivo models are needed to fully understand the tumor suppressive effect of SWI/SNF components.

In addition, oncogenic cooperation has still not been explored. In HCC, ARID2 mutations have been associated with $\mathrm{HCV}$ infection and with B-catenin activating mutations in CTNNB1. This can be correlated with the fact that CTNNB1-mutated HCC are mostly associated with non-viral and HCV etiologies [47,76]. A better understanding on how ARID2 mutations could be elicited in a context of HCV infection, and/or how chromatin remodeling cooperates with Wnt/B-catenin signaling in ARID2 and CTNNB1-mutated HCC is required. Interestingly, this subset of HCCs forms a group independent of the TP53-mutated one, as it occurs in ARID2-mutated non-small cell lung carcinoma [40]. This mutual exclusion of ARID2 and TP53 mutations in cancer is to be further studied. 


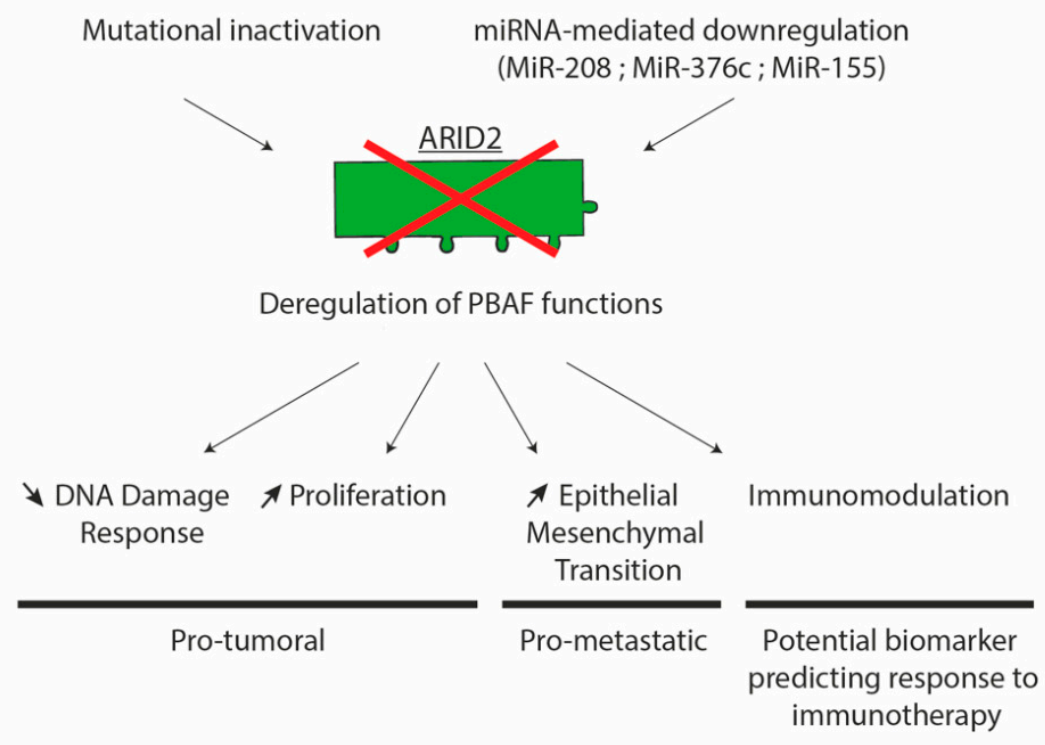

Figure 4. Potential impact of ARID2 loss in HCC.

The involvement of ARID2 mutations, and more widely the disruption of chromatin regulatory processes in cancer, point towards the need for anti-cancer therapies targeted on chromatin-associated proteins. With that in mind, genome-scale synthetic lethal studies have been undertaken in a wide spectrum of cancer model systems, using either RNA-interference or CRISPR-Cas9 editing [77]. They already identified dependencies specific to chromatin remodeling components and such an approach should be conducted in HCC models bearing alterations in chromatin remodelers like ARID2 [78]. In this matter, it is of interest to study the interaction between the different canonical SWI/SNF complexes (BAF and PBAF) as well as the recently described non-canonical BAF complex (ncBAF) [78] which has been described as free from any ARID subunit (ARID1A/B, ARID2). We can hypothesize that the loss of a subunit specific to one of the three complexes can alter the distribution and the amount of the others, thus explaining both the changes in gene expression and the dependency on other complexes for tumorigenesis.

Lastly, immunotherapy combined with TKI treatment is a promising therapeutic avenue for HCC. ARID2 has been recently thought of as modulating the tumor immune landscape in HCC [79]. Given the fact that the loss of ARID2 makes melanoma cells more sensitive to immunotherapies, it is now necessary to investigate the role of ARID2 as a biomarker predicting HCC response to immunotherapy.

Author Contributions: R.L., L.C. and S.C. wrote the manuscript. R.L. designed the figures, with the help of L.C., R.L. and S.C. performed the revisions. All authors have read and agreed to the published version of the manuscript.

Funding: Ligue Nationale Contre le Cancer, Paris, France. RL had a grant from the Fondation pour la Recherche Médicale, France.

Conflicts of Interest: The authors declare no conflict of interest.

\section{References}

1. Arnaudo, A.M.; Garcia, B.A. Proteomic characterization of novel histone post-translational modifications. Epigenetics Chromatin 2013, 6, 24. [CrossRef] [PubMed]

2. Kadoch, C.; Hargreaves, D.C.; Hodges, C.; Elias, L.; Ho, L.; Ranish, J.; Crabtree, G.R. Proteomic and bioinformatic analysis of mammalian SWI/SNF complexes identifies extensive roles in human malignancy. Nat. Genet. 2013, 45, 592-601. [CrossRef] [PubMed]

3. Kadoch, C.; Crabtree, G.R. Mammalian SWI/SNF chromatin remodeling complexes and cancer: Mechanistic insights gained from human genomics. Sci. Adv. 2015, 1, e1500447. [CrossRef] [PubMed] 
4. Neigeborn, L.; Carlson, M. Genes Affecting the Regulation of SUC2 Gene Expression by Glucose Repression in SACCHAROMYCES CEREVISIAE. Genetics 1984, 108, 845-858.

5. Stern, M.; Jensen, R.; Herskowitz, I. Five SWI genes are required for expression of the HO gene in yeast. J. Mol. Boil. 1984, 178, 853-868. [CrossRef]

6. Schuettengruber, B.; Bourbon, H.-M.; Di Croce, L.; Cavalli, G. Genome Regulation by Polycomb and Trithorax: 70 Years and Counting. Cell 2017, 171,34-57. [CrossRef]

7. Krüger, W.; Peterson, C.L.; Sil, A.; Coburn, C.; Arents, G.; Moudrianakis, E.N.; Herskowitz, I. Amino acid substitutions in the structured domains of histones $\mathrm{H} 3$ and $\mathrm{H} 4$ partially relieve the requirement of the yeast SWI/SNF complex for transcription. Genes Dev. 1995, 9, 2770-2779. [CrossRef]

8. Sternberg, P.W.; Stern, M.J.; Clark, I.; Herskowitz, I. Activation of the yeast HO gene by release from multiple negative controls. Cell 1987, 48,567-577. [CrossRef]

9. He, S.; Wu, Z.; Tian, Y.; Yu, Z.; Yu, J.; Wang, X.; Li, J.; Liu, B.; Xu, Y. Structure of nucleosome-bound human BAF complex. Science 2020, 367, 875-881. [CrossRef]

10. Narlikar, G.J.; Fan, H.-Y.; Kingston, R.E. Cooperation between Complexes that Regulate Chromatin Structure and Transcription. Cell 2002, 108, 475-487. [CrossRef]

11. Dilworth, F.J.; Fromental, C.; Yamamoto, K.; Chambon, P. ATP-Driven Chromatin Remodeling Activity and Histone Acetyltransferases Act Sequentially during Transactivation by RAR/RXR In Vitro. Mol. Cell 2000, 6, 1049-1058. [CrossRef]

12. Stanton, B.Z.; Hodges, C.; Calarco, J.P.; Braun, S.M.G.; Ku, W.L.; Kadoch, C.; Zhao, K.; Crabtree, G.R. Smarca4 ATPase mutations disrupt direct eviction of PRC1 from chromatin. Nat. Genet. 2016, 49, 282-288. [CrossRef] [PubMed]

13. Kadoch, C.; Williams, R.T.; Calarco, J.P.; Miller, E.L.; Weber, C.M.; Braun, S.M.G.; Pulice, J.L.; Chory, E.J.; Crabtree, G.R. Dynamics of BAF-Polycomb complex opposition on heterochromatin in normal and oncogenic states. Nat. Genet. 2016, 49, 213-222. [CrossRef] [PubMed]

14. Pan, J.; McKenzie, Z.M.; D'Avino, A.R.; Mashtalir, N.; Lareau, C.A.; Pierre, R.S.; Wang, L.; Shilatifard, A.; Kadoch, C. The ATPase module of mammalian SWI/SNF family complexes mediates subcomplex identity and catalytic activity-independent genomic targeting. Nat. Genet. 2019, 51, 618-626. [CrossRef] [PubMed]

15. Versteege, I.; Sévenet, N.; Lange, J.; Rousseau-Merck, M.F.; Ambros, P.; Handgretinger, R.; Aurias, A.; Delattre, O. Truncating mutations of hSNF5/INI1 in aggressive paediatric cancer. Nature 1998, 394, $203-206$. [CrossRef] [PubMed]

16. Mittal, P.; Roberts, C.W.M. The SWI/SNF complex in cancer-biology, biomarkers and therapy. Nat. Rev. Clin. Oncol. 2020, 17, 435-448. [CrossRef] [PubMed]

17. Zhao, H.; Wang, J.; Han, Y.; Huang, Z.; Ying, J.; Bi, X.; Zhao, J.; Fang, Y.; Zhou, H.; Zhou, J.; et al. ARID2: A new tumor suppressor gene in hepatocellular carcinoma. Oncotarget 2011, 2, 886-891. [CrossRef]

18. Li, M.; Zhao, H.; Zhang, X.; Wood, L.D.; Anders, R.A.; Choti, M.A.; Pawlik, T.M.; Daniel, H.D.; Kannangai, R.; Offerhaus, G.J.A.; et al. Inactivating mutations of the chromatin remodeling gene ARID2 in hepatocellular carcinoma. Nat. Genet. 2011, 43, 828-829. [CrossRef]

19. Zhang, X.; Azhar, G.; Zhong, Y.; Wei, J.Y. Zipzap/p200 is a novel zinc finger protein contributing to cardiac gene regulation. Biochem. Biophys. Res. Commun. 2006, 346, 794-801. [CrossRef]

20. Wilsker, D.; Probst, L.; Wain, H.M.; Maltais, L.; Tucker, P.W.; Moran, E. Nomenclature of the ARID family of DNA-binding proteins. Genomics 2005, 86, 242-251. [CrossRef]

21. Patsialou, A.; Wilsker, D.; Moran, E. DNA-binding properties of ARID family proteins. Nucleic Acids Res. 2005, 33, 66-80. [CrossRef] [PubMed]

22. Emery, P.; Durand, B.; Mach, B.; Reith, W. RFX Proteins, a Novel Family of DNA Binding Proteins Conserved in the Eukaryotic Kingdom. Nucleic Acids Res. 1996, 24, 803-807. [CrossRef]

23. Mashtalir, N.; D'Avino, A.; Michel, B.C.; Luo, J.; Pan, J.; Otto, J.E.; Zullow, H.J.; McKenzie, Z.M.; Kubiak, R.L.; Pierre, R.S.; et al. Modular Organization and Assembly of SWI/SNF Family Chromatin Remodeling Complexes. Cell 2018, 175, 1272-1288.e20. [CrossRef] [PubMed]

24. Yan, Z.; Cui, K.; Murray, D.M.; Ling, C.; Xue, Y.; Gerstein, A.; Parsons, R.; Zhao, K.; Wang, W. PBAF chromatin-remodeling complex requires a novel specificity subunit, BAF200, to regulate expression of selective interferon-responsive genes. Genes Dev. 2005, 19, 1662-1667. [CrossRef] [PubMed] 
25. Pan, D.; Kobayashi, A.; Jiang, P.; De Andrade, L.F.; Tay, R.E.; Luoma, A.M.; Tsoucas, D.; Qiu, X.; Lim, K.; Rao, P.; et al. A major chromatin regulator determines resistance of tumor cells to T cell-mediated killing. Science 2018, 359, 770-775. [CrossRef]

26. Xu, F.; Flowers, S.; Moran, E. Essential Role of ARID2 Protein-containing SWI/SNF Complex in Tissue-specific Gene Expression. J. Boil. Chem. 2011, 287, 5033-5041. [CrossRef]

27. He, L.; Tian, X.; Zhang, H.; Hu, T.; Huang, X.; Zhang, L.; Wang, Z.; Zhou, B. BAF200 Is Required for Heart Morphogenesis and Coronary Artery Development. PLoS ONE 2014, 9, e109493. [CrossRef]

28. Liu, L.; Wan, X.; Zhou, P.; Zhou, X.; Zhang, W.; Hui, X.; Yuan, X.; Ding, X.; Zhu, R.; Meng, G.; et al. The chromatin remodeling subunit Baf200 promotes normal hematopoiesis and inhibits leukemogenesis. J. Hematol. Oncol. 2018, 11, 1-16. [CrossRef]

29. Cui, K.; Tailor, P.; Liu, H.; Chen, X.; Ozato, K.; Zhao, K. The Chromatin-Remodeling BAF Complex Mediates Cellular Antiviral Activities by Promoter Priming. Mol. Cell. Boil. 2004, 24, 4476-4486. [CrossRef]

30. Pattenden, S.G.; Klose, R.; Karaskov, E.; Bremner, R. Interferon-gamma-induced chromatin remodeling at the CIITA locus is BRG1 dependent. EMBO J. 2002, 21, 1978-1986. [CrossRef]

31. Liu, H.; Kang, H.; Liu, R.; Chen, X.; Zhao, K. Maximal Induction of a Subset of Interferon Target Genes Requires the Chromatin-Remodeling Activity of the BAF Complex. Mol. Cell. Boil. 2002, 22, 6471-6479. [CrossRef] [PubMed]

32. Huang, M.; Qian, F.; Hu, Y.; Ang, C.; Li, Z.; Wen, Z. Chromatin-remodelling factor BRG1 selectively activates a subset of interferon- $\alpha$-inducible genes. Nat. Cell Biol. 2002, 4, 774-781. [CrossRef] [PubMed]

33. Agalioti, T.; Chen, G.; Thanos, D. Deciphering the Transcriptional Histone Acetylation Code for a Human Gene. Cell 2002, 111, 381-392. [CrossRef]

34. Kakarougkas, A.; Ismail, A.; Chambers, A.L.; Riballo, E.; Herbert, A.D.; Künzel, J.; Löbrich, M.; Jeggo, P.A.; Downs, J.A. Requirement for PBAF in Transcriptional Repression and Repair at DNA Breaks in Actively Transcribed Regions of Chromatin. Mol. Cell 2014, 55, 723-732. [CrossRef] [PubMed]

35. De Castro, R.O.; Previato, L.; Goitea, V.; Felberg, A.; Guiraldelli, M.F.; Filiberti, A.; Pezza, R.J. The chromatin-remodeling subunit Baf200 promotes homology-directed DNA repair and regulates distinct chromatin-remodeling complexes. J. Boil. Chem. 2017, 292, 8459-8471. [CrossRef]

36. Perenthaler, E.; Yousefi, S.; Niggl, E.; Barakat, T.S. Beyond the Exome: The Non-coding Genome and Enhancers in Neurodevelopmental Disorders and Malformations of Cortical Development. Front. Cell. Neurosci. 2019, 13, 352. [CrossRef]

37. Khazanchi, R.; Ronspies, C.A.; Smith, S.C.; Starr, L.J. Patient with anomalous skin pigmentation expands the phenotype of ARID2 loss-of-function disorder, a SWI/SNF-related intellectual disability. Am. J. Med Genet. Part A 2019, 179, 808-812. [CrossRef]

38. Bramswig, N.C.; Caluseriu, O.; Lüdecke, H.-J.; Bolduc, F.V.; Noel, N.C.L.; Wieland, T.; Surowy, H.; Christen, H.-J.; Engels, H.; Strom, T.M.; et al. Heterozygosity for ARID2 loss-of-function mutations in individuals with a Coffin-Siris syndrome-like phenotype. Hum. Genet. 2017, 136, 297-305. [CrossRef]

39. Takeda, H.; Kataoka, S.; Nakayama, M.; Ali, M.A.E.; Oshima, H.; Yamamoto, D.; Park, J.-W.; Takegami, Y.; An, T.; Jenkins, N.A.; et al. CRISPR-Cas9-mediated gene knockout in intestinal tumor organoids provides functional validation for colorectal cancer driver genes. Proc. Natl. Acad. Sci. USA 2019, 116, 15635-15644. [CrossRef]

40. Manceau, G.; Letouzé, E.; Guichard, C.; Didelot, A.; Cazes, A.; Corte, H.; Fabre, E.; Pallier, K.; Imbeaud, S.; Le Pimpec-Barthes, F.; et al. Recurrent inactivating mutations ofARID2in non-small cell lung carcinoma. Int. J. Cancer 2012, 132, 2217-2221. [CrossRef]

41. Hodis, E.; Watson, I.R.; Kryukov, G.V.; Arold, S.T.; Imielinski, M.; Theurillat, J.-P.; Nickerson, E.; Auclair, D.; Li, L.; Place, C.; et al. A Landscape of Driver Mutations in Melanoma. Cell 2012, 150, 251-263. [CrossRef] [PubMed]

42. Betz, B.L.; Strobeck, M.W.; Reisman, D.N.; Knudsen, E.S.; Weissman, B.E. Re-expression of hSNF5/INI1/BAF47 in pediatric tumor cells leads to G1arrest associated with induction of p16ink4a and activation of RB. Oncogene 2002, 21, 5193-5203. [CrossRef] [PubMed]

43. Karnezis, A.N.; Wang, Y.; Ramos, P.; Hendricks, W.; Oliva, E.; D’Angelo, E.; Prat, J.; Nucci, M.R.; Nielsen, T.O.; Chow, C.; et al. Dual loss of the SWI/SNF complex ATPases SMARCA4/BRG1 and SMARCA2/BRM is highly sensitive and specific for small cell carcinoma of the ovary, hypercalcaemic type: SMARCA4/SMARCA2 loss in small cell carcinoma, hypercalcaemic type. J. Pathol. 2016, 238, 389-400. [CrossRef] [PubMed] 
44. Miao, D.; Margolis, C.A.; Gao, W.; Voss, M.H.; Li, W.; Martini, D.J.; Norton, C.; Bossé, D.; Wankowicz, S.A.; Cullen, D.; et al. Genomic correlates of response to immune checkpoint therapies in clear cell renal cell carcinoma. Science 2018, 359, 801-806. [CrossRef]

45. Pinyol, R.; Montal, R.; Bassaganyas, L.; Sia, D.; Takayama, T.; Chau, G.-Y.; Mazzaferro, V.; Roayaie, S.; Lee, H.C.; Kokudo, N.; et al. Molecular predictors of prevention of recurrence in HCC with sorafenib as adjuvant treatment and prognostic factors in the phase 3 STORM trial. Gut 2018, 68, 1065-1075. [CrossRef]

46. Llovet, J.M.; Zucman-Rossi, J.; Pikarsky, E.; Sangro, B.; Schwartz, M.; Sherman, M.; Gores, G. Hepatocellular carcinoma. Nat. Rev. Dis. Prim. 2016, 2, 16019. [CrossRef]

47. Fujimoto, A.; Totoki, Y.; Abe, T.; Boroevich, K.A.; Hosoda, F.; Nguyen, H.H.; Aoki, M.; Hosono, N.; Kubo, M.; Miya, F.; et al. Whole-genome sequencing of liver cancers identifies etiological influences on mutation patterns and recurrent mutations in chromatin regulators. Nat. Genet. 2012, 44, 760-764. [CrossRef]

48. Guichard, C.; Amaddeo, G.; Imbeaud, S.; Ladeiro, Y.; Pelletier, L.; Ben Maad, I.; Calderaro, J.; Bioulac-Sage, P.; Letexier, M.; Degos, F.; et al. Integrated analysis of somatic mutations and focal copy-number changes identifies key genes and pathways in hepatocellular carcinoma. Nat. Genet. 2012, 44, 694-698. [CrossRef]

49. Huang, J.; Deng, Q.; Wang, Q.; Li, K.-Y.; Dai, J.-H.; Li, N.; Zhu, Z.-D.; Zhou, B.; Liu, X.-Y.; Liu, R.-F.; et al. Exome sequencing of hepatitis B virus-associated hepatocellular carcinoma. Nat. Genet. 2012, 44, 1117-1121. [CrossRef]

50. Schulze, K.; Imbeaud, S.; Letouzé, E.; Alexandrov, L.B.; Calderaro, J.; Rebouissou, S.; Couchy, G.; Meiller, C.; Shinde, J.; Soysouvanh, F.; et al. Exome sequencing of hepatocellular carcinomas identifies new mutational signatures and potential therapeutic targets. Nat. Genet. 2015, 47, 505-511. [CrossRef]

51. Nault, J.-C.; Zucman-Rossi, J. Genetics of hepatocellular carcinoma: The next generation. J. Hepatol. 2014, 60, 224-226. [CrossRef] [PubMed]

52. Rebouissou, S.; Nault, J.-C. Advances in molecular classification and precision oncology in hepatocellular carcinoma. J. Hepatol. 2020, 72, 215-229. [CrossRef] [PubMed]

53. He, B.; Zhao, Z.; Cai, Q.; Zhang, Y.; Zhang, P.; Shi, S.; Xie, H.; Peng, X.; Yin, W.; Tao, Y.; et al. miRNA-based biomarkers, therapies, and resistance in Cancer. Int. J. Boil. Sci. 2020, 16, 2628-2647. [CrossRef] [PubMed]

54. Yu, P.; Wu, D.; You, Y.; Sun, J.; Lu, L.; Tan, J.; Bie, P. miR-208-3p promotes hepatocellular carcinoma cell proliferation and invasion through regulating ARID2 expression. Exp. Cell Res. 2015, 336, 232-241. [CrossRef]

55. Wang, Y.; Chang, W.; Chang, W.; Chang, X.; Zhai, S.; Pan, G.; Dang, S. MicroRNA-376c-3p Facilitates Human Hepatocellular Carcinoma Progression via Repressing AT-Rich Interaction Domain 2. J. Cancer 2018, 9, 4187-4196. [CrossRef] [PubMed]

56. Li, H.; Zheng, D.; Zhang, B.; Liu, L.; Ou, J.; Chen, W.; Xiong, S.; Gu, Y.; Yang, J. Mir-208 promotes cell proliferation by repressing SOX6 expression in human esophageal squamous cell carcinoma. J. Transl. Med. 2014, 12, 196. [CrossRef] [PubMed]

57. Liu, A.; Shao, C.; Jin, G.; Liu, R.; Hao, J.; Song, B.; Ouyang, L.; Hu, X. miR-208-Induced Epithelial to Mesenchymal Transition of Pancreatic Cancer Cells Promotes Cell Metastasis and Invasion. Cell Biophys. 2014, 69, 341-346. [CrossRef]

58. Wu, H.; Xu, L.; Chen, Y.; Xu, C. MiR-208a-3p functions as an oncogene in colorectal cancer by targeting PDCD4. Biosci. Rep. 2019, 39. [CrossRef]

59. Yin, K.; Liu, M.; Zhang, M.; Wang, F.; Fen, M.; Liu, Z.; Yuan, Y.; Gao, S.; Yang, L.; Zhang, W.; et al. miR-208a-3p suppresses cell apoptosis by targeting PDCD4 in gastric cancer. Oncotarget 2016, 7, 67321-67332. [CrossRef]

60. Liu, L.; Wang, W.; Gao, S.; Wang, X. MicroRNA-208a directly targets Src kinase signaling inhibitor 1 to facilitate cell proliferation and invasion in non-small cell lung cancer. Mol. Med. Rep. 2019, 20, 3140-3148. [CrossRef]

61. Ye, G.; Fu, G.; Cui, S.; Zhao, S.; Bernaudo, S.; Bai, Y.; Ding, Y.; Zhang, Y.; Yang, B.B.; Peng, C. MicroRNA 376c enhances ovarian cancer cell survival by targeting activin receptor-like kinase 7: Implications for chemoresistance. J. Cell Sci. 2011, 124, 359-368. [CrossRef] [PubMed]

62. Zhang, Y.-H.; Fu, J.; Zhang, Z.-J.; Ge, C.-C.; Yi, Y. LncRNA-LINC00152 down-regulated by miR-376c-3p restricts viability and promotes apoptosis of colorectal cancer cells. Am. J. Transl. Res. 2016, 8, 5286-5297. [PubMed]

63. Zehavi, L.; Avraham, R.; Barzilai, A.; Bar-Ilan, D.; Navon, R.; Sidi, Y.; Avni, D.; Leibowitz-Amit, R. Silencing of a large microRNA cluster on human chromosome 14q32 in melanoma: Biological effects of mir-376a and mir-376c on insulin growth factor 1 receptor. Mol. Cancer 2012, 11, 44. [CrossRef] [PubMed] 
64. Wang, G.; Dong, F.; Xu, Z.; Sharma, S.; Hu, X.; Chen, D.; Zhang, J.; Zhang, J.; Dong, Q. MicroRNA profile in HBV-induced infection and hepatocellular carcinoma. BMC Cancer 2017, 17, 805-811. [CrossRef]

65. Gulei, D.; Raduly, L.; Broseghini, E.; Ferracin, M.; Berindan-Neagoe, I. The extensive role of miR-155 in malignant and non-malignant diseases. Mol. Asp. Med. 2019, 70, 33-56. [CrossRef]

66. Fu, X.; Wen, H.; Jing, L.; Yang, Y.; Wang, W.; Liang, X.; Nan, K.; Yao, Y.; Tian, T. MicroRNA-155-5p promotes hepatocellular carcinoma progression by suppressing PTEN through the PI3K/Akt pathway. Cancer Sci. 2017, 108, 620-631. [CrossRef]

67. Sun, J.-F.; Zhang, N.; Gao, C.-J.; Zhang, Y.-W.; Dai, Q.-S. Exosome-Mediated MiR-155 Transfer Contributes to Hepatocellular Carcinoma Cell Proliferation by Targeting PTEN. Med. Sci. Monit. Basic Res. 2019, 25, 218-228. [CrossRef]

68. Li, D.-P.; Fan, J.; Wu, Y.-J.; Xie, Y.-F.; Zha, J.-M.; Zhou, X.-M. MiR-155 up-regulated by TGF- $\beta$ promotes epithelial-mesenchymal transition, invasion and metastasis of human hepatocellular carcinoma cells in vitro. Am. J. Transl. Res. 2017, 9, 2956-2965.

69. Zhang, Y.; Wei, W.; Cheng, N.; Wang, K.; Li, B.; Jiang, X.; Sun, S. Hepatitis C virus-induced up-regulation of microRNA-155 promotes hepatocarcinogenesis by activating Wnt signaling. Hepatology 2012, 56, 1631-1640. [CrossRef]

70. Tang, B.; Lei, B.; Qi, G.; Liang, X.; Tang, F.; Yuan, S.; Wang, Z.; Yu, S.; He, S. MicroRNA-155-3p promotes hepatocellular carcinoma formation by suppressing FBXW7 expression. J. Exp. Clin. Cancer Res. 2016, 35, 93. [CrossRef]

71. Wu, M.; Duan, Q.; Liu, X.; Zhang, P.; Fu, Y.; Zhang, Z.; Liu, L.; Cheng, J.; Jiang, H. MiR-155-5p promotes oral cancer progression by targeting chromatin remodeling gene ARID2. Biomed. Pharmacother. 2019, 122, 109696. [CrossRef] [PubMed]

72. Yin, Q.; McBride, J.; Fewell, C.; Lacey, M.; Wang, X.; Lin, Z.; Cameron, J.E.; Flemington, E.K. MicroRNA-155 Is an Epstein-Barr Virus-Induced Gene That Modulates Epstein-Barr Virus-Regulated Gene Expression Pathways. J. Virol. 2008, 82, 5295-5306. [CrossRef] [PubMed]

73. Duan, Y.; Tian, L.; Gao, Q.; Liang, L.; Zhang, W.; Yang, Y.; Zheng, Y.; Pan, E.; Li, S.; Tang, N. Chromatin remodeling gene ARID2 targets cyclin D1 and cyclin E1 to suppress hepatoma cell progression. Oncotarget 2016, 7, 45863-45875. [CrossRef] [PubMed]

74. Jiang, H.; Cao, H.-J.; Ma, N.; Bao, W.-D.; Wang, J.-J.; Chen, T.-W.; Zhang, E.-B.; Yuan, Y.-M.; Ni, Q.-Z.; Zhang, F.-K.; et al. Chromatin remodeling factor ARID2 suppresses hepatocellular carcinoma metastasis via DNMT1-Snail axis. Proc. Natl. Acad. Sci. USA 2020, 117, 4770-4780. [CrossRef]

75. Oba, A.; Shimada, S.; Akiyama, Y.; Nishikawaji, T.; Mogushi, K.; Ito, H.; Matsumura, S.; Aihara, A.; Mitsunori, Y.; Ban, D.; et al. ARID2 modulates DNA damage response in human hepatocellular carcinoma cells. J. Hepatol. 2017, 66, 942-951. [CrossRef]

76. Boyault, S.; Rickman, D.S.; De Reyniès, A.; Balabaud, C.; Rebouissou, S.; Jeannot, E.; Hérault, A.; Saric, J.; Belghiti, J.; Franco, D.; et al. Transcriptome classification of HCC is related to gene alterations and to new therapeutic targets. Hepatology 2007, 45, 42-52. [CrossRef]

77. Valencia, A.M.; Kadoch, C. Chromatin regulatory mechanisms and therapeutic opportunities in cancer. Nat. Cell Biol. 2019, 21, 152-161. [CrossRef]

78. Michel, B.C.; D'Avino, A.; Cassel, S.H.; Mashtalir, N.; McKenzie, Z.M.; McBride, M.; Valencia, A.M.; Zhou, Q.; Bocker, M.; Soares, L.M.M.; et al. A non-canonical SWI/SNF complex is a synthetic lethal target in cancers driven by BAF complex perturbation. Nat. Cell Biol. 2018, 20, 1410-1420. [CrossRef]

79. Fujita, M.; Yamaguchi, R.; Hasegawa, T.; Shimada, S.; Arihiro, K.; Hayashi, S.; Maejima, K.; Nakano, K.; Fujimoto, A.; Ono, A.; et al. Classification of primary liver cancer with immunosuppression mechanisms and correlation with genomic alterations. EBioMedicine 2020, 53, 102659. [CrossRef]

(C) 2020 by the authors. Licensee MDPI, Basel, Switzerland. This article is an open access article distributed under the terms and conditions of the Creative Commons Attribution (CC BY) license (http://creativecommons.org/licenses/by/4.0/). 